\title{
Presence of Low Dose of Fludarabine in Cultures Blocks Regulatory T Cell Expansion and Maintains Tumor-Specific Cytotoxic T Lymphocyte Activity Generated with Peripheral Blood Lymphocytes
}

\author{
Upendra Hegde $^{\mathrm{a}}$ Arvind Chhabra $^{\mathrm{a}}$ Subhasis Chattopadhyay ${ }^{\mathrm{b}}$ Raja Das $^{\mathrm{a}}$ \\ Swagatam Ray ${ }^{a}$ Nitya G. Chakraborty ${ }^{a}$ \\ a Department of Medicine, Carole and Ray Neag Comprehensive Cancer Center, and bepartment of Immunology, \\ University of Connecticut Health Center, Farmington, Conn., USA
}

\section{Key Words}

Cytotoxic T lymphocytes $\cdot$ Cytokine $\cdot$ Melanoma $\cdot$

Peripheral blood lymphocytes

\begin{abstract}
Background: For tumor vaccine-based immunotherapy of cancer, the expansion of tumor antigen-specific cytotoxic $T$ lymphocytes (CTL) in the patients by blocking induced regulatory $\mathrm{T}$ (Treg) cells is the most important objective now. Fludarabine (FLU), a known anticancer drug, has been shown to downregulate Treg cells in vivo in chronic leukemia patients. Melanoma tumor antigen Mart- $1_{27-35}$-specific CD8+ CTLs generated in vitro with total peripheral blood lymphocytes (PBL) lose their activity within 14-21 days with concomitant expansion of Treg cells. When CD4+ cells are removed from PBL and CTL are generated with purified CD8+ cells, the CTL survive and maintain their activity for a significantly longer period. Methods: We used a low dose of FLU in the cultures in Mart-1-specific CTL generation assays with total PBL. Blood samples were taken from HLA-A2-positive melanoma patients and normal donors. Autologous matured dendritic cells pulsed with Mart- $1_{27-35}$ peptide were used to generate CTL responses using purified CD8+ cells or total PBL. Results: The presence of FLU in the cultures with PBL helped to generate a significantly higher number of an-
\end{abstract}

\section{KARGER}

Fax +4161306 1234

E-Mail karger@karger.ch

www.karger.com
(C) 2008 S. Karger AG, Basel

$1015-2008 / 08 / 0753-0200 \$ 24.50 / 0$

Accessible online at:

www.karger.com/pat tigen-specific CTLs as detected by Mart-1 HLA-A2 tetramer staining. Specificity of such CTLs was determined by IFN- $\gamma$ secretion or by cytotoxicity against the target cells bearing the specific antigen. The presence of FLU stopped the expansion of IL-10-producing CD4+ Treg cells in the cultures with PBL. Analyses of expanded CD4+ cells isolated from PBL in vitro cocultures with FLU showed a Th1 type of function. Those cells secreted higher amounts of IFN- $\gamma$ and very low levels of IL-10, or no IL-10 at all, upon restimulation. Conclusion: The observations of the study are as important for adaptive immunotherapy of cancer as they are for vaccinebased approaches.

Copyright $\odot 2008$ S. Karger AG, Basel

\section{Introduction}

Amongst all mechanisms of immune evasion, tumor tolerance by $\mathrm{T}$ cells through normal pathways of self-tolerance generation [1-7] appears to be the toughest one. This represents a significant challenge to successful cancer immunotherapy with vaccine-induced cytotoxic $\mathrm{T}$ lymphocyte (CTL) response. To achieve effective antitumor activity, therapeutic vaccines must be capable of overcoming or reversing $\mathrm{T}$ cell tolerance to tumor antigens, whether the tolerance is via naturally occurring

Nitya G. Chakraborty

University of Connecticut Health Center

263 Farmington Ave

Farmington, CT 06030-1628 (USA)

Tel. +1 860679 1446, Fax +1 860679 4451, E-Mail chakraborty@uchc.edu 
$\mathrm{CD} 4+\mathrm{CD} 25+\mathrm{T}$ regulatory (Treg) cells $[8,9]$ or by induced Treg cells (induced from CD4+CD25- cells) $[10$, 11]. Previously, we have shown that tumor-specific CTL generated in vitro with total peripheral blood lymphocytes (PBL) declined within 2-3 weeks with a concomitant expansion of suppressor-type CD4+ cells (Treg) secreting IL-10 [12]. We have also shown that the number of vaccine-induced CTLs decreases in the patients, with a concomitant increase in a class of CD4+CD25+ cells that demonstrated intracellular IL-10 [13]. In order to overcome the negative role played by $\mathrm{Th} 2 / \mathrm{Th} 3$, presently termed Trl-type activated CD4+ cells, use of adjuvant, multiple peptides (class I and II), viruses [14-16] and Tolllike receptors are being introduced $[17,18]$ along with vaccine therapy. In our previous report we have shown that the Th1 conditioning of the total PBL with IL-12 and anti-IL-4 antibody, might help to induce better tumorspecific CTL survivability and activity for a prolonged period in cultures [19]. Use of a combination of IL-12 and anti-IL-4 antibody in patients induces adverse toxicity, so there is a need of an alternate approach. In an animal model system, North et al. [20] have shown that a suboptimum dose of cyclophosphamide could block the expansion of CD4+ suppressor cells. In the human leukemia system, it has been shown that the use of fludarabine (FLU) or cyclophosphamide in vivo or in vitro could lower the number of circulating Treg cells [21-24]. In general, the known mechanism of action of FLU is by dephosphorylation and followed by phosphorylation inside the cells and eventually through the deoxycytidine kinase $(\mathrm{dCK})$ pathway $[23,24]$. But differential action of FLU on activated CD4/CD8 is not known. We show for the first time that in a tumor antigen-specific CTL generation assay, use of a very low dose of FLU could block induction and expansion of Treg cells and offer a longer life of tumor antigen-specific CTL.

\section{Materials and Methods}

Clinical Samples and the Drug

Blood samples from 3 HLA-A2 patients with metastatic melanoma and 3 normal donors were taken for the study. Informed consent was obtained from all participants. Patients were out of therapy for at least 3 months. If available, a small piece of surgically removed tumor was also taken from the patients who provided informed consent. The details of the collection of samples and tumor cell preparation have been described previously [12, 13]. FLU phosphate used in the cultures is produced by SICOR Pharmaceuticals Inc. (Irvine, Calif., USA) and was purchased from the pharmacy at our Health Center.

Th1 Conditioning and Longer-Lasting CTL Activity
Tissue Culture

Tissue culture technique and the procedure of isolating fresh tumor cells from tissue explants have been described before [12, $25,26]$. Briefly, tissue cultures were performed in Iscove's medium (Life Technologies Inc., Grand Island, N.Y., USA) supplemented with $10 \%$ fetal bovine serum (Gemini Bio-Products Inc., Calabasas, Calif., USA), L-arginine (0.55 mM), L-asparagine (0.24 $\mathrm{mM}$ ) and L-glutamine (1.5 nM; all from Life Technologies), henceforth described as complete medium.

\section{T Cell Purification}

CD4+ and CD8+ T cells were purified using magnetic beads as per protocol (Dynal Biotech ASA, Oslo, Norway) provided by the company and as described earlier $[25,26]$.

\section{Dendritic Cell Culture}

Dendritic cells (DCs) used in this study were isolated from peripheral myeloid antigen-presenting cells (APC) expanded in vitro as described earlier [25, 26]. Briefly, monocytes/macrophages were isolated as adherent cells from Ficoll-Hypaque gradient-derived mononuclear cell populations from blood. The adherent cells were then cultured in complete medium containing $1,000 \mathrm{U} / \mathrm{ml}$ of GM-CSF (Immunex Corp., Seattle, Wash., USA), and 1,000 U/ml of IL-4 (R\&D Systems, Minneapolis, Minn., USA) for 7 days. The nonadherent and loosely adherent cells were harvested by vigorous washing.

In vitro Coculture to Generate CTL from PBL or CD8+ T Cells PBL or CD8+ T cells were cocultured with antigen-pulsed DC or tumor cells as described earlier $[12,25,26]$.

\section{Phenotypic Analysis}

The immunofluorescence procedure for phenotypic analysis by flow cytometry has been described before $[12,25,26]$.

\section{Proliferation Assay}

Proliferation of PBL with phytohemagglutinin (PHA) and anti-CD3 antibody was done by radioactive thymidine ( $\left.\mathrm{H}^{3} \mathrm{TdR}\right)$ incorporation according to the method described previously [12].

\section{Cytokine ELISA and Intracellular Cytokine Assay}

Analyses of cytokine-secreting properties with responder cells were done by using an HLA-A2-positive TAP-deficient T2 cell line as previously described $[25,26]$. For CD4+ cells, autologous or allogeneic DC or other nonspecific stimulants were used. IFN- $\gamma$, IL- 4 and IL-10 cytokines were assayed in appropriate ELISA assays according to the manufacturer's protocol (Duo Set ELISA Development System; R\&D Systems) and as described earlier $[12,25,26]$. Intracellular cytokine assay was done as described by Chakraborty et al. [12].

\section{Tetramer Assay}

Analysis for the Mart- $1_{27-35}$ antigen-specific $\mathrm{T}$ cell receptor bearing CD8+ cells has been described previously $[12,25,26]$. Briefly, the cells from in vitro cocultures (IVC) were washed twice in PBS and then incubated with $1 \mu \mathrm{l}$ of allophycocyanin-conjugated Mart-1 27-35 -HLA-A2 tetramer (Beckman Coulter Inc., Fullerton, Calif., USA) and CD8 FITC or PE (BD Biosciences, San Diego, Calif., USA) at room temperature for $30 \mathrm{~min}$. The effector 
Table 1. Dose-response analysis with FLU with PBL, taken from normal donors and melanoma patients

\begin{tabular}{|c|c|c|c|c|c|c|c|c|c|c|c|c|c|c|c|}
\hline & \multicolumn{15}{|c|}{$90 \%$ or higher viability of PBL in culture for $48 \mathrm{~h}$ with the drug, $\mu \mathrm{g} / \mathrm{ml}$} \\
\hline & 1,000 & 500 & 250 & 125 & 62 & 31 & 16 & 8 & 4 & 2 & 1 & 0.5 & 0.25 & 0.125 & 0.062 \\
\hline
\end{tabular}
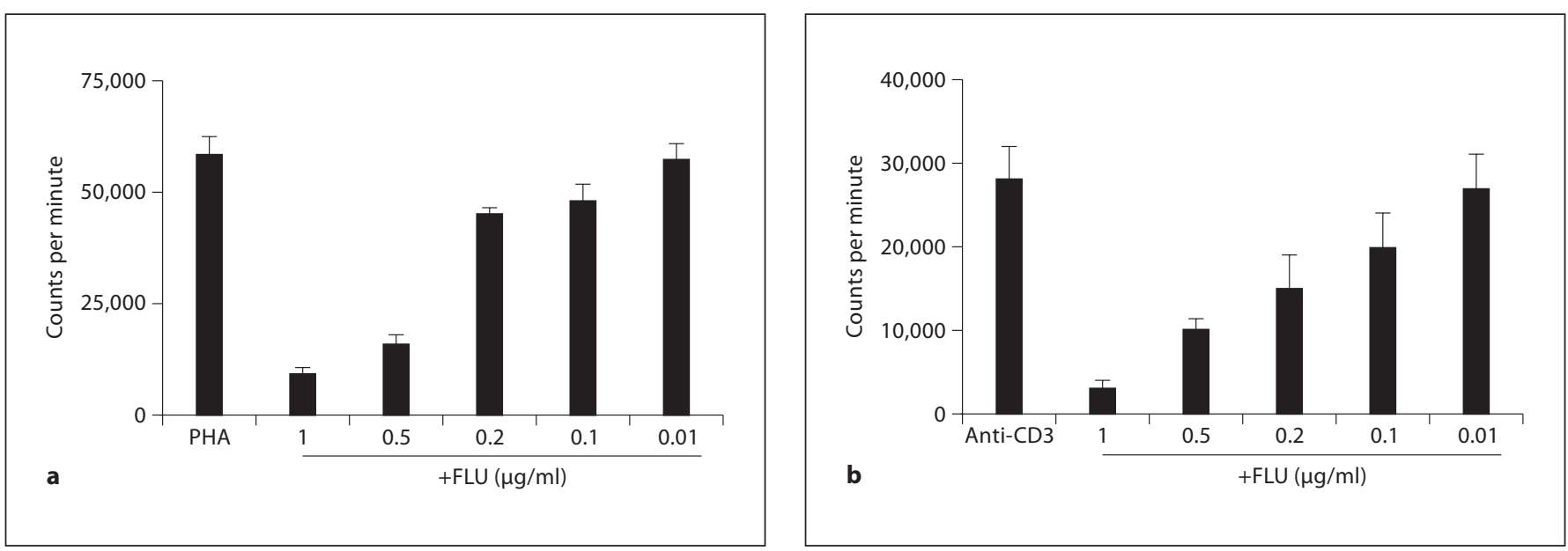

Fig. 1. Functional characterization of PBL after FLU treatment in culture. a Proliferation of PBL in response to PHA $(2 \mu \mathrm{g} / \mathrm{ml})$ in the absence and presence of FLU. b Proliferation of PBL upon stimulation with anti CD3 Ab in the absence and presence of FLU. Data are represented as counts per minute \pm SD.

cells were again washed twice and resuspended in FACS buffer. Thereafter, the number of tetramer-positive cells was determined by flow cytometry using FACS Calibur (Becton Dickinson, Mountain View, Calif., USA), and the acquired cytofluorographic data were analyzed using Cell Quest software (Becton Dickinson).

\section{Statistical Analysis}

Statistical analyses of data were performed, the significance was determined by Student's t test and $\mathrm{p}<0.01-0.05$ was considered to be significant.

\section{Results}

Test for Viability and Function of PBL after in vitro Exposure to FLU

Previously, it was shown by Beyer et al. [23] that due to the presence of as low as $10 \mu \mathrm{M} / \mathrm{ml}$ of FLU in culture, about $52 \%$ of CD $4+C D 25-$ cells and $70 \%$ of CD $4+C D 25+$ cells became anexin positive within $48 \mathrm{~h}$. In another experiment, Gamberale et al. [24] showed that both CD8 and CD4 cells are susceptible to $1-25 \mu \mathrm{M}$ of FLU in cul- tures; $1 \mu \mathrm{M}$ is about $360 \mathrm{ng} / \mathrm{ml}$. In order to identify a concentration of the drug FLU at which PBL would be viable and functional, we tested several concentrations of FLU in culture and found that $90 \%$ or more cells from PBL remained viable after $48 \mathrm{~h}$ at the dose of $100 \mathrm{ng} / \mathrm{ml}$ (table 1). Experiments were done with PBLs from all donors and each donor was tested at least twice. We then tested this particular dose of FLU and lower concentrations kept continuously in culture to see at which dose the PBL remain functionally active. We first treated PBL with several doses of FLU in culture for 7 days, performed a proliferation assay with the treated PBL (without washing off the drug) and compared that with untreated PBL kept in medium for 7 days. Control PBL and FLU-treated PBL were then stimulated with either $2 \mu \mathrm{g} / \mathrm{ml}$ of PHA or $2 \mu \mathrm{g}$ of plate-bound anti-CD3 antibody in a flat-bottom 96well tissue culture plate as described [12]. Figure 1 describes the proliferative ability of PBL after treatment with the various doses of the drug. Figure la shows the proliferation of PBL with PHA in the presence and absence of FLU. Figure $1 \mathrm{~b}$ shows the proliferation of PBL 
Fig. 2. Mart- $1_{27-35}$-specific CTL generation from PBL IVC and CD8 IVC. a Number of CD8+Mart-1 $27-35$ tetramer-positive T cells in PBL IVC in medium on days 7 and 28 as dot plot analysis by flow cytometry. b Number of Mart- $1_{27-35}$ tetramerspecific CTLs from CD8 IVC on days 7 and 28 as analyzed as dot plot analysis by flow cytometry. c Number of CD8+ and Mart- $1_{27-35}$ tetramer-positive cells from PBL IVC in the presence of FLU on days 7 and 28 as analyzed as dot plot analysis by flow cytometry.

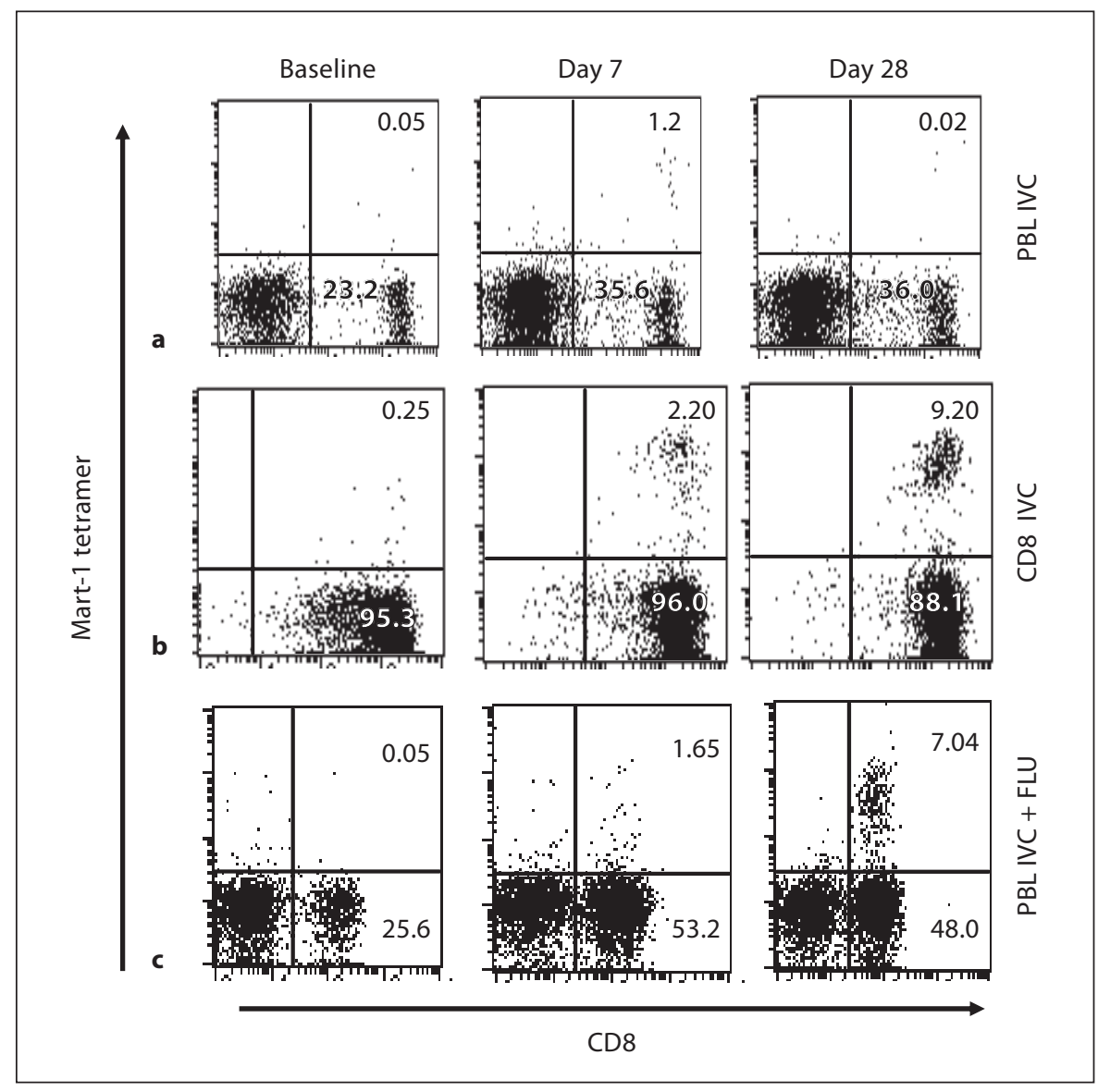

with anti-CD3 antibody in the presence and absence of FLU. As can be seen, the proliferative ability of PBL maintained in the presence of the drug $\left(10 \mathrm{ng} / \mathrm{ml} / 2 \times 10^{5}\right.$ cells $)$ is comparable with that of untreated PBL. Therefore, in subsequent experiments we used this concentration (10 $\mathrm{ng} / \mathrm{ml} / 1 \times 10^{5}$ cells) of the drug. Proliferation experiments were done with PBL from all 6 donors with triplicate wells for each condition. $\mathrm{H}^{3} \mathrm{TdR}$ incorporation was measured by counts per minute \pm SD. In untreated PBLs after PHA stimulation, counts varied from 48,000 to 75,000 in different donors, whereas after anti-CD3 antibody stimulation, it varied from 20,000 to 40,000 . We present the data with PBL from a patient who is not currently under any treatment and who has currently no detectable disease, but is at high risk for recurrence.

\section{Expansion of Tumor Antigen-Specific CTL Response in Cocultures}

Freshly isolated PBL and purified CD8+ cells were analyzed for the percentage of Mart-1-specific CTL precursors by tetramer analysis. Figure 2 is a representative ex- periment of Mart-1 tetramer-positive cells from expansion cultures with total PBL and purified CD8+ cells (purity $98 \pm 2 \%$ ). Expansion of specific CTL precursors was done in IVC with PBL and purified CD8+ T cells and with irradiated autologous DC pulsed with peptides (Mart- $1_{27-35}$ ) in the presence of $50 \mathrm{U} / \mathrm{ml}$ of IL-2. Antigenspecific CTL from IVCs with PBL and purified CD8+ T cells were analyzed on days 7 and 28 after the initiation of the cultures. The cultures were restimulated with appropriate stimuli every 7-10 days. Column 1 of figure 2 shows the baseline Mart-1 tetramer-positive CD8+ cells on the day of the start of IVC. Column 2 represents the numbers of expanded Mart-1 tetramer-positive CD8+ cells after 7 days of culture. Column 3 represents the numbers of Mart-1 tetramer-positive CD8+ cells after 28 days of culture. A significant expansion of antigen-specific CD8+ cells was observed in the cultures with purified CD8+ cells as well as in cultures with total PBL. However, the number of Mart-1 tetramer-positive cells form total CD8+ cells decreased to baseline values (or lower) in the control cultures with total PBL (row a of 
Table 2. Cytokine production (IFN- $\gamma, \mathrm{pg} / \mathrm{ml}$ ) by activated cells when restimulated with T2, T2 + Mage- $3_{271-279}$ or T2 + Mart- $1_{27-35}$

\begin{tabular}{lccc}
\hline Cell source & T2 alone & T2 + Mage- $3_{271-279}$ & T2 + Mart- $1_{27-35}$ \\
\hline Control PBL IVC day 7 & $25 \pm 8$ & $20 \pm 10$ & $115 \pm 35$ \\
Control PBL IVC day 14 & $5 \pm 2$ & $15 \pm 5$ & $300 \pm 50$ \\
Control PBL IVC day 28 & $10 \pm 5$ & $15 \pm 4$ & $20 \pm 5$ \\
\hline PBL IVC in presence of FLU day 7 & $50 \pm 18$ & $80 \pm 45$ & $220 \pm 55$ \\
PBL IVC in presence of FLU day 14 & 0 & 0 & $330 \pm 75$ \\
PBL IVC in presence of FLU day 28 & 0 & 0 & $350 \pm 66$ \\
\hline
\end{tabular}

Table 3. Cytotoxicity assay with IVC with total PBL after 28 days of initiation of the culture

\begin{tabular}{|c|c|c|c|c|c|}
\hline \multirow[t]{2}{*}{ Effector } & \multirow[t]{2}{*}{ Target cells } & \multicolumn{4}{|c|}{ Lysis at E:T } \\
\hline & & $40 \%$ & $20 \%$ & $10 \%$ & $5 \%$ \\
\hline \multirow[t]{6}{*}{ PBL IVC } & $\mathrm{T} 2$ & 0 & 0 & 0 & 0 \\
\hline & $\mathrm{T} 2$ + Mart-1 pep & $5.6 \pm 2.1$ & 0 & 0 & 0 \\
\hline & $\mathrm{T} 2+$ Cone pep & 0 & 0 & 0 & 0 \\
\hline & PT-M & 0 & 0 & 0 & 0 \\
\hline & PT-M + anti-class I Ab & 0 & NT & NT & NT \\
\hline & PT-M + anti-class II Ab & 0 & NT & NT & NT \\
\hline \multirow[t]{6}{*}{ PBL IVC + FLU } & $\mathrm{T} 2$ & 0 & 0 & 0 & 0 \\
\hline & $\mathrm{T} 2+$ Mart-1 pep & $40.2 \pm 10.1$ & $30.6 \pm 7.9$ & $18.4 \pm 5.1$ & $6.9 \pm 2.8$ \\
\hline & $\mathrm{T} 2+$ Cone pep & 2.0 & 0 & 0 & 0 \\
\hline & PT-M & $26.6 \pm 6.9$ & $27.4 \pm 7.8$ & $17.4 \pm 4.6$ & $10.2 \pm 4.6$ \\
\hline & PT-M + anti-class I Ab & 4.0 & NT & NT & NT \\
\hline & PT-M + anti-class II Ab & $28.4 \pm 11.3$ & NT & NT & NT \\
\hline
\end{tabular}

$\mathrm{E}: \mathrm{T}=$ Effector:target $;$ pep = peptide $\mathrm{Ab}=$ antibody $\mathrm{NT}=$ not tested.

fig. 2), whereas the number of Mart-1 tetramer-positive cells continued to expand after 28 days in IVC with purified CD8+ cells (row b of fig. 2). Interestingly, in the cultures with total PBL where FLU was present, the number of tetramer-positive CD8+ cells remained significantly higher $(\mathrm{p}<0.05)$ after 28 days (row c of fig. 2). It is of note, however, that the fluorescence intensity of the CD8+ cells and corresponding tetramer staining appeared to be low where FLU was present in the cultures, although the same amount and same batch of CD8 antibody with PE and Mart-1 tetramer with APC were used for all experiments (row c of fig. 2). Figure 2 is a representative of experiments with 3 patients and 3 normal donors. Each donor was bled 3 times to run 3 sets of experiments. Initially, before any stimulation, the percentage of Mart- 1 tetramer-positive CD8+ cells varied from 0.01 to 0.1 .

\section{Presence of FLU Maintained Functional CTLs}

Generated in Cultures with Total PBL

We further studied whether the effect of the drug in cultures with PBL from patients and normal donors could keep the functional activity of expanded CTL in cultures. The cultures were fed every other day with appropriate cytokine and with and without the drug, and were restimulated with appropriate stimuli every 7-10 days. Cytokine secretion assays were done 14 and 28 days after the initiation of the cultures. The statistical comparison of the data was done within the different conditions of the cultures with PBL and these were then further compared with IVCs with CD8+ cells. Tables 2 and 3 represent the data of IFN- $\gamma$ response and cytotoxicity assays, respectively, with the expanded populations. For cytokine assays, after 14 and 28 days, some of the cells were removed from the cultures and washed 3 times in PBS to remove 

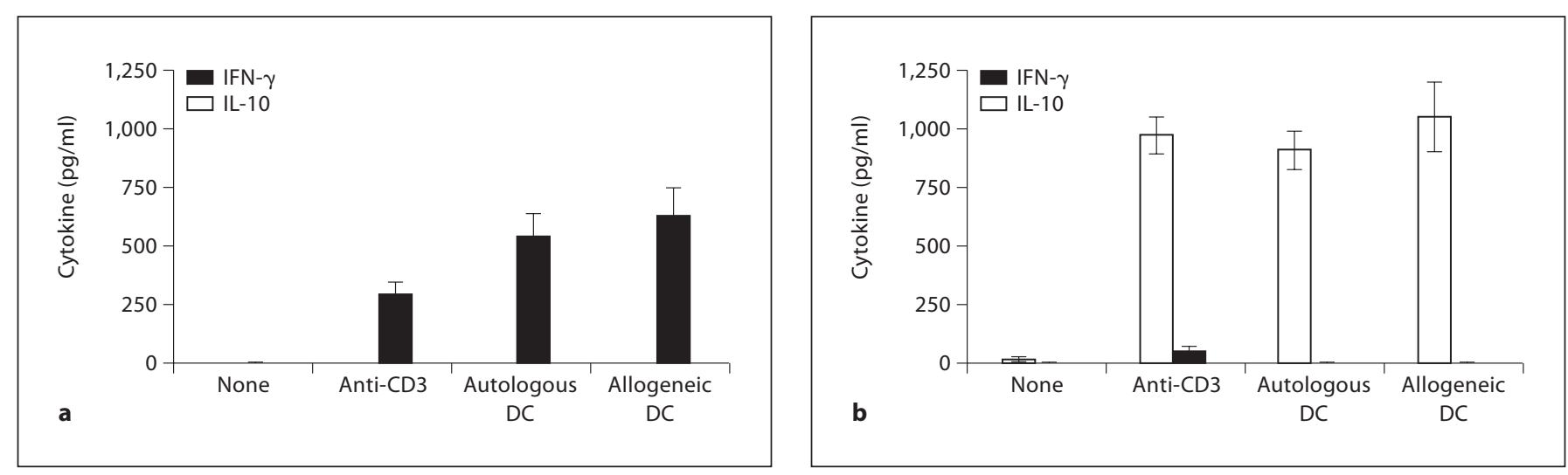

Fig. 3. Cytokine ELISA for IFN- $\gamma$ and IL-10 secreted by CD4+ cells taken from IVCs: after 28 days of initiation, CD4+ cells taken from PBL IVCs were tested for cytokine production upon stimulation. a Cytokine production by CD4+ cells taken from PBL cocultures in the presence of FLU and restimulated with no DC, autologous DC and allogeneic DC. $\mathbf{b}$ Cytokine production by CD4+ cells taken from control PBL cocultures and restimulated with no CD, autologous DC and allogeneic DC.

cell surface-bound cytokines. These cells were then counted and stimulated separately in 96-well plates $(1 \times$ $10^{5}$ cells/well) with T2 cells pulsed with Mart-1 peptide or a control peptide, or with T2 cells alone (responder: stimulator $=10: 1$ ). After $24 \mathrm{~h}$ the supernatants from the wells were collected and cytokine assays by ELISA for IFN- $\gamma$ and IL-10 were performed. Whether normal donor or patients, we detected the highest level of IFN- $\gamma$ secretion by a single Mart-1 antigen-specific cell in all cultures with total PBL as detected by higher mean fluorescence intensity (MFI) of IFN- $\gamma$ antibody stain by Mart-1-positive cells (cumulative data not shown). Although with the majority of donors we saw a decline in CTL activity from day 14 onwards, in few donors we detected that the decline in CTL starts much earlier. Interestingly, in the cultures with total PBL where FLU was present, we did not find MFI for intracellular IFN- $\gamma$ to be higher than that of the control cultures, but the production of IFN- $\gamma$ by antigen-specific cells was maintained beyond day 28 of the cultures as evident from table 2 .

Table 2 represents the data with PBL only and with PBL where FLU was present. From table 2, it is clear that the presence of FLU generated better antigen-specific cytokine-producing cells when compared with unconditioned PBL IVC. In some of the control PBL IVCs, IFN$\gamma$-producing ability was totally lost and the difference found using the different culture conditions was very significant $(\mathrm{p}<0.05)$.

The expanded antigen-specific cells in the cultures with FLU continued to be functional for a longer period compared to control PBL cultures in an auto-DC-based restimulation system. We have also observed (table 3 ) a significantly elevated cytolytic activity of the responder cells from PBL IVC with FLU against both Mart- $1_{27-35}$ peptide-pulsed target T2 and against a Mart-1-positive HLA-A2+ tumor cell line PT-M (naturally processed antigen). It was observed that the antigen-specific killing was HLA-A2 restricted and killing was blocked in presence of anti-HLA-A2 antibody. The extent of the killing of the target cells was very significant at all effector-totarget ratios used, since the cytotoxicity assay was done in the presence of a 50 -fold excess of cold K-562 cells $(\mathrm{p}<0.02)$.

\section{Characterization of Activated CD4+Cells Induced in} the PBL IVCs

We further wanted to analyze the expanded CD4+ cells taken 28 days after the initiation of the cultures with PBL. CD4+ cells from cultures with PBL IVC and PBL IVC with FLU were purified by positive selection with Dynal beads. The CD4+ cells were then restimulated with plate-bound anti-CD3, with irradiated autologous DC and allogeneic DC with responder:stimulator $=10: 1$. About $2 \times 10^{5}$ cells of CD4+ cells $(\times 3)$ were stimulated in a 96-well plate with a total volume of $200 \mu \mathrm{l}$ for $24 \mathrm{~h}$. Supernatant from the cultures was collected and analyzed for cytokines by using ELISA kits. Figure 3 describes that the CD4+ cells taken from the PBL cultures from all individuals tested here generated mainly IL-10producing cells (fig. $3 \mathrm{~b}$ ) and no IFN- $\gamma$-producing cells, 
indicating a Tr1-type of cell induction in the cultures. In contrast, the CD4+ cells taken from the cultures where the drug FLU was present generated mainly Th1-type CD4+ cells secreting a significant amount of IFN- $\gamma$ upon restimulation (fig. 3a). We further confirmed this observation in an intracellular cytokine assay with the expanded Trl type of cells in figure 4 . Figure 4 describes the intracellular IL-10 and IFN- $\gamma$ produced by CD $4+$ cells taken out after 28 days of culture and restimulated with appropriate stimuli. It is evident that there is spontaneous production of intracellular IL-10 in these Trl-type cells and virtually no significant level of IFN- $\gamma$ even after restimulation (fig. $4 \mathrm{c}$ and $\mathrm{d}$ ). It is important to point out here that freshly isolated CD4+ cells from each individual secreted reasonable amounts of IFN- $\gamma$ when stimulated with allogeneic DC (cumulative data not shown).

\section{Discussion}

FLU is a chemotherapeutic agent, an analogue of adenosine which is dephosphorylated by membrane ectonucleotidases, used to treat hematologic cancers $[27,28]$. The high doses of the drug that are required for effective chemotherapy lead to immunosuppression, a property that is the basis for its other clinical uses, such as preventing graft-versus-host disease in bone marrow transplantation, minimizing chances of organ rejection in organ transplantation [29, 30]. Although FLU can cause immunosuppression, low doses of the drug can lead to enhanced immune responses against a variety of antigens $[30,31]$. We have recently reported that naturally occurring Treg cells are not a major impediment against the expansion of tumor-specific CTL, whereas induced Treg cells induced from CD4+CD25- are [11]. In this regard, blocking the induction and expansion of induced Treg cells in cultures by using low dose of FLU is important. Although it has been previously reported that a low dose of FLU can lead to enhanced immune responses [31], we are reporting for the first time on the use of the drug in inducing tumor antigen-specific CTL response from PBL in cultures. FLU mainly acts on dividing cells and after entering the cells it is phosphorylated by dCK. The differential responses to low dose of FLU by activated CD4/ CD8 cells or by different subsets of CD4 cells is not known, however, it is obvious that the optimal immunemodulating doses for a chemotherapeutic agent should be not only just above the doses that begin to induce cytopenia, but also keep the cells functional (especially in vitro). We postulate that the mechanism of action of FLU

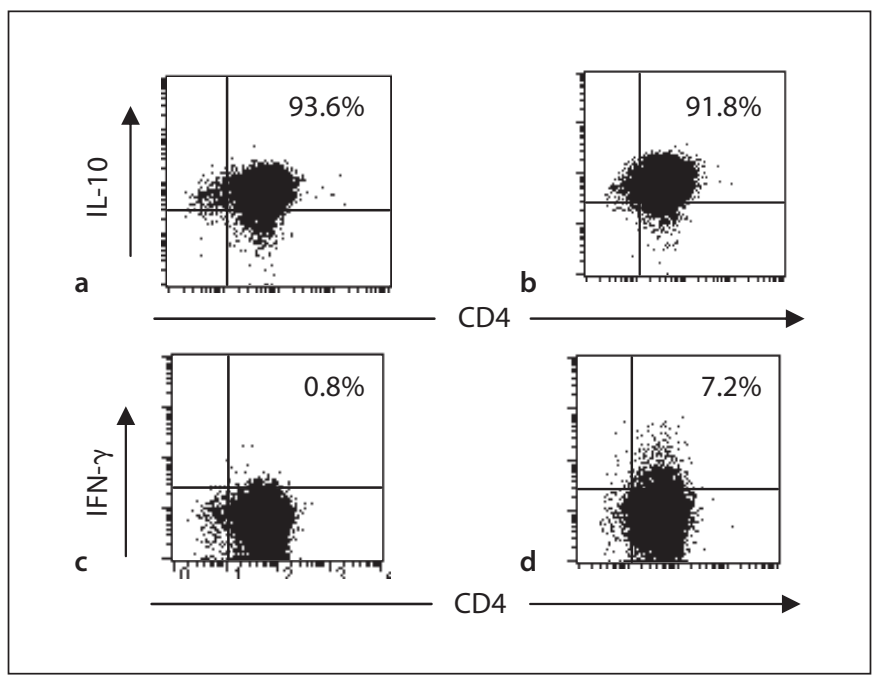

Fig. 4. Intracellular cytokine profile in activated CD4+ Tr1-type cells from control IVC. a, b Intracellular IL-10 before and after restimulation of Tr1 type of CD4+ cells obtained from control PBL IVC. c, $\mathbf{d}$ Intracellular IFN- $\gamma$ before and after restimulation of Tr1 type of CD4+ cells obtained from control PBL IVC.

on induced Treg cells is to block the proliferation of these cells due to the differential expression of CD73 or at dCK level. Whatever the mechanism, the present study demonstrates for the first time that FLU used in very low doses in culture has a direct inhibitory effect on induction/expansion of Treg cells. Our data allow us to begin discussing possible mechanisms of action of these drugs at its sub-suboptimal dose, whether in vitro or in vivo, in patients along with vaccine therapy. Reports on Treg cells have shown that Treg cells that secrete IL-10 or TGF- $\beta$ occupy an interesting place in the schema of tumor immunotherapy $[3,4]$. Previously, we have shown that in in vitro CTL generation assays with tumor-specific MHC I peptides with total PBL, CTLs could be induced but are short lived. From 2 weeks after initiation, the number of CTLs declined and the number of CD4+ Treg-type cells increased [12]. We have also shown that even vaccine-induced CTL response in patients decreased with a concomitant increase in CD4+ T cells having high expression of CD25 with significant expression of intracellular IL-10 [13]. The secretion of IL-10 by those activated CD4+ cells from CTL induction cultures was found to be specific for self-APC and could be blocked by anti-MHC II antibody on APC [12]. However, in this study we did not detect such specificity for self-MHC II. It is known that apart from therapy of chronic leukemia, FLU has been used in transplantations to prevent graft-versus-host dis- 
ease. In this respect, the recently published work by $\mathrm{Ni}$ shioka et al. [32] about blocking of Th1-type cells by FLU is important. No matter in which way the drug is being used, to create cytopenia for elimination of Th1 or blocking of Th2/Th3/ Tr1, the dose of the drug plays a key role. In the present observation, when PBL from patients or from normal donors are used, the presence of very low dose of FLU helped to maintain the quality and number of induced CTLs in the cultures for a significantly longer period (tables 2,3). In vivo, the tumor microenvironment is still a black box, but the in vitro experiments presented here and some results with patients with FLU [21-24, 2931] indicate that the presence of FLU might stop a cascade of reactions that might start the expansion of tolerance inducers, whether specific [12] or nonspecific [13, present study]. In this connection, lower MFI on CD8+ cells from PBL cultures with FLU invite detailed analysis of those CD8+ cells in terms of their various surface markers.
In order to establish metastatic tumors, expansion of a population of Treg cells is required and those cells could be induced from a noncommitted CD4+ cell population $[10,11]$. If the presence of an already approved chemotherapeutic agent like FLU used at a suboptimum dose could block the induction of fresh Treg or Tr1 cells from CD4+CD25- cells or block the expansion of already existing Treg cells, this could theoretically help the expansion of tumor-specific CTLs in vivo, and make vaccine therapy for cancer successful.

\section{Acknowledgement}

We thank Dr. Robert B. Clark for valuable input in preparation of the manuscript. This work was supported by grant MO1RR06192 from GCRC, University of Connecticut Health Center.

\section{References}

$>_{1}$ Torre-Amione G, Beauchamp RD, Koeppen H, Park BH, Schreiber H, Moses HL, Rowley DA: A highly immunogenic tumor transfected with a murine transforming growth factor type $1 \mathrm{cDNA}$ escapes immune surveillance. Proc Natl Acad Sci USA 1990;87: 1486-1490.

-2 Restifo NP, Esquivel F, Kawakami Y, Yewdell JW, Mule JJ, Rosenberg SA, Bennink JR: Identification of human cancers deficient in antigen processing. J Exp Med 1993;177: 265-272.

-3 Beck C, Schreiber H, Rowley D: Role of TGF$\beta$ in immune-evasion of cancer. Microsc Res Tech 2001;52:387-395.

4 Salazar-Onfray F: Interleukin-10: a cytokine used by tumors to escape immunosurveillance. Med Oncol 1999;16:86-94.

5 Takahashi T, Sakaguchi S: Naturally arising $\mathrm{CD} 25+\mathrm{CD} 4+$ regulatory $\mathrm{T}$ cells in maintaining immunologic self-tolerance and preventing autoimmune disease. Curr Mol Med 2003;3:693-706.

6 Kuwana M: Induction of anergic and regulatory $\mathrm{T}$ cells by plasmacytoid dendritic cells and other dendritic cell subsets. Hum Immunol 2002;63:1156-1163.

-7 Chang CC, Ciubotariu R, Manavalan JS, Yuan J, Colovai AI, Piazza F, Lederman S, Colonna M, Cortesini R, Dalla-Favera R, Suciu-Foca N: Tolerization of dendritic cells by $\mathrm{T}(\mathrm{S})$ cells: the crucial role of inhibitory receptors ILT3 and ILT4. Nat Immunol 2002;3: 237-243.

Th1 Conditioning and Longer-Lasting CTL Activity
8 Wang HY, Lee DA, Peng G, Guo Z, Li Y, Kiniwa Y, Shevach EM, Wang RF: Tumor specific human CD4+ regulatory $\mathrm{T}$ cells and their ligands: implications for immunotherapy. Immunity 2004;20:107-118.

-9 Curiel TJ, Coukos G, Zou L, Alvarez X, Cheng P, Mottram P, Evdemon-Hogan M, Conejo-Garcia JR, Zhang L, Burow M, Zhu Y, Wei S, Kryczek I, Daniel B, Gordon A, Myers L, Lackner A, Disis ML, Knutson KL, Chen L, Zou W: Specific recruitment of regulatory $\mathrm{T}$ cells in ovarian carcinoma fosters immune privilege and predicts reduced survival. Nat Med 2004;10:942-949.

10 Chattopadhyay S, Chakraborty NG, Mukherji B: Regulatory T cell and tumor immunity. Cancer Immunol Immunother 2005; 54:1153-1161.

11 Chattopadhyay S, Mehrotra S, Chhabra A, Hegde U, Mukherji B, Chakraborty NG: Effect of CD4+CD25+ and CD4+CD25-T regulatory cells on the generation of cytolytic $\mathrm{T}$ cell response to a self but human tumor associated epitope in vitro. J Immunol 2006; 176:984-990.

12 Chakraborty NG, Li L, Sporn JR, Kurtzman SH, Ergin MT, Mukherji B: Emergence of regulatory $\mathrm{CD} 4+\mathrm{T}$ cell response to repetitive stimulation with antigen-presenting cells in vitro: implications in designing antigen-presenting cell-based tumor vaccines. J Immunol 1999;162:5576-5583.

13 Chakraborty NG, Chattopadhyay S, Mehorotra S, Chhabra A, Mukherji B: Regulatory $\mathrm{T}$ cell response and vaccine induced CTL response in human melanoma. Hum Immunol 2004;65:794-802.
14 Mayordomo JI, Zorina T, Storkus WJ, Zitvogel L, Celluzzi C, Falo LD, Melief CJ, Ildstad ST, Kast WM, Deleo AB, et al: Bone marrowderived dendritic cells pulsed with synthetic tumour peptides elicit protective and therapeutic antitumour immunity. Nat Med 1995; 1:1297-1302.

15 Nestle FO, Alijagic S, Gilliet M, Sun Y, Grabbe S, Dummer R, Burg G, Schadendorf D: Vaccination of melanoma patients with peptide- or tumor lysate-pulsed dendritic cells. Nat Med 1998;4:328-332.

16 Specht JM, Wang G, Do MT, Lam JS, Royal RE, Reeves ME, Rosenberg SA, Hwu P: Dendritic cells retrovirally transduced with a model antigen gene are therapeutically effective against established pulmonary metastases. J Exp Med 1997;186:1213-1221.

17 Dabbagh K, Lewis DB: Toll-like receptors and T-helper-1/T-helper-2 responses. Curr Opin Infect Dis 2003;16:199-204.

18 Yang Y, Huang CT, Huang X, Pardoll DM: Persistent Toll-like receptor signals are required for reversal of regulatory $\mathrm{T}$ cell-mediated CD8 tolerance. Nat Immunol 2004;5: 508-515.

19 Chattopadhyay S, Chakraborty NG: Continuous presence of Th1 conditions are necessary for longer lasting tumor antigen specific CTL activity in stimulation culture with PBL. Hum Immunol 2005;66:884-891.

20 North RJ, Digiacomo A, Dye ES: Suppression of antitumor immunity; in Otter WD, Ruitenberg EJ (eds): Tumor Immunology, Mechanisms, Diagnosis, Therapy. Amsterdam, Elsevier Science Publishers, 1987. 
21 Lutsiak Christine ME, Semnani RT, Pascalis RD, Kashmiri SVS, Schlom J, Sabzevani H: Inhibition of CD4+CD25+ $\mathrm{T}$ regulatory cell function implicated in enhanced immune response by low-dose cyclophosphamide. Blood 2005;105:2862-2868.

-22 Wright SJ, Robertson LE, O’Brian S, Plunkett W and Keating MJ: Role of fludarabine in hematologic malignancies. Blood 1994;8: 125-134.

-23 Beyer M, Kochanek M, Darabi K, et al: Reduced frequencies and suppressive function of CD4+CD25+ regulatory $\mathrm{T}$ cells in patients with chronic lymphocytic leukemia after therapy with fludarabine. Blood 2005;106: 2018-2025.

24 Gamberale R, Galmarini CM, FernandezCalotti P, Jordheim L, Sanchez-Avalos J, Dumontet C, Geffner J, Giordano M: In vitro susceptibility of CD4+ and CD8+ T cell subsets to fludarabine. Biochem Pharmacol 2003;66:2185-2191.
25 Mehrotra S, Chhabra A, Chattopadhyay S, Dorsky DI, Chakraborty NG, Mukherji B: Rescuing melanoma epitope-specific cytolytic T lymphocytes from activation-induced cell death, by SP600125, an inhibitor of JNK: implications in cancer immunotherapy. J Immunol 2004;173:6017-6024.

26 Mehrotra S, Stevens R, Zengou R, Chakraborty NG, Butterfield LH, Economou JS, Dorsky DI, Mukherji B: Regulation of melanoma epitope-specific cytolytic $\mathrm{T}$ lymphocyte response by immature and activated dendritic cells, in vitro. Cancer Res 2003;63:5607-5614.

27 Keating MJ, Kantarjian H, Talpaz M, Redman J, Koller C, Barloie B, Valeaquez W, Plunkett W, Freireich EJ, McCredie KB: Fludarabine: a new agent with major activity against chronic lymphocytic leukemia. Blood 1989;74:19-25.

28 Young JL Jr, Percy CL, Asire AJ, et al: Cancer incidence and mortality in the United States, 1973-77. Natl Cancer Inst Monogr 1981;57: $1-187$.
29 O’Brien S, del Giglio A, Keating M: Advances in the biology and treatment of B-cell chronic lymphocytic leukemia. Blood 1995; 85:307-318.

30 Rozman C, Montserrat E: Chronic lymphocytic leukemia. N Engl J Med 1995;333: 1052-1057.

31 Wendtner CM, Schmitt B, Bergmann M, Rohnisch T, Buhmann R, Hallek M: New aspects on the pathogenesis, diagnostic procedures, and therapeutic management of chronic lymphocytic leukemia. Int J Hematol 2001;73:32-38.

32 Nishioka C, Ikezoe T, Togitani K, Yokoyama A: Fludarabine induces growth arrest and apoptosis of cytokine- or alloantigen-stimulated peripheral blood mononuclear cells, and decreases production of Th1 cytokines via inhibition of nuclear factor $\kappa \mathrm{B}$. Bone Marrow Transplant 2008;41:303-309. 